\title{
Utility of intravenous catheters for femoral arterial cannulation in infants having complicated sternal re-entry
}

\author{
Brian Kogon, MD, ${ }^{a}$ Jordan Voss, CCP, ${ }^{\mathrm{b}}$ Craig Villari, BS, ${ }^{\text {a }}$ Neil Shah, BS, ${ }^{a}$ Kathy Spitzer, CCP, ${ }^{\mathrm{b}}$ Marney Moore, CCP,
} AnnMarie McGoldrick, CCP, ${ }^{b}$ Paul Kirshbom, MD, and Kirk Kanter, MD ${ }^{a}$

From the Departments of Pediatric Cardiothoracic Surgery ${ }^{\mathrm{a}}$ and Perfusion, ${ }^{\mathrm{b}}$ Emory University, Atlanta, Ga.

Received for publication March 20, 2007; revisions received April 20, 2007; accepted for publication May 9, 2007.

Address for reprints: Brian Kogon, MD, Egleston Hospital, Children's Healthcare of Atlanta, Atlanta, GA (E-mail: brian kogon@emoryhealthcare.org)

J Thorac Cardiovasc Surg 2007;134:746-9

$0022-5223 / \$ 32.00$

Copyright $\odot 2007$ by The American Association for Thoracic Surgery

doi:10.1016/j.jtcvs.2007.05.012
Objective: Many children undergoing surgery for congenital heart disease have had prior operations. Reoperative sternotomy carries with it the risk of cardiac injury and the need for emergency peripheral cannulation. Unfortunately, in smaller children, many of the standard sites are occluded, stenosed, or too small for the smallest manufactured cannulas. Using a model, we evaluated the feasibility of using peripheral intravenous catheters for establishing cardiopulmonary support.

Methods: A model cardiopulmonary bypass circuit was created. Catheters of varying diameter and length were used to simulate arterial cannulation. With each catheter, flows were incrementally increased until a maximum arterial line pressure was achieved. Data were recorded.

Results: Catheter diameters increased from 24 to 14 gauge, and catheter lengths increased from 1 inch to 1.88 inches. Flow could not be established through the 24 -gauge catheter without an unacceptably high arterial line pressure. From the next smallest catheter (22 gauge $\times 1$ inch) to the largest catheter (14 gauge $\times 1.88$ inches), maximum achievable flow rates ranged from 70 to $540 \mathrm{~mL} / \mathrm{min}$, respectively.

Conclusions: Peripheral arterial cannulation may be lifesaving in cases of complicated sternal re-entry in children. Intravenous catheters can be used when vessels are too small for standard cannulas. Flow rates that provide adequate support while maintaining acceptable arterial line pressures are achievable with peripheral intravenous catheters until central cannulation can be accomplished safely.

$\mathrm{M}$ any children undergoing surgery for congenital heart disease have had prior operations. Reoperative sternotomy carries with it the risk of cardiac injury and the need for emergency peripheral cannulation. Unfortunately, in smaller children, many of the standard sites are occluded, stenosed, or too small for the smallest manufactured cannulas. In these instances, peripheral intravenous catheters can be used for arterial access until central cannulation can be accomplished safely.

\section{Materials and Methods}

A cardiopulmonary bypass circuit was created (Figure 1). A 1-L intravenous fluid bag was used to simulate a patient. The following components, starting from the fluid bag, were then used to complete the model cardiopulmonary bypass circuit: decanting spike, 3 -foot length of 1/4-inch $\times$ 3/32-inch SMA tubing, Cobe Century heart-lung machine with arterial roller pump (COBE Cardiovascular, Inc, Arvada, Colo), Dideco D736 Micro Arterial Line Filter $40 \mu$ (Sorin group Italia Srl, Mirandola Modena, Italy), 3.5-inch length of 3/16-inch $\times$ 3/16-inch SMA tubing (COBE Cardiovascular), perfusion adapter, and selected BD Angiocath intravenous catheters (BD Medical, Medical Surgical Systems, Franklin Lakes, NJ).

Three pressure transducers were set up within the system. Patient pressure (pressure 1) was measured with a DLP pressure monitoring system (Medtronic, Inc, Minneapolis, Minn). 


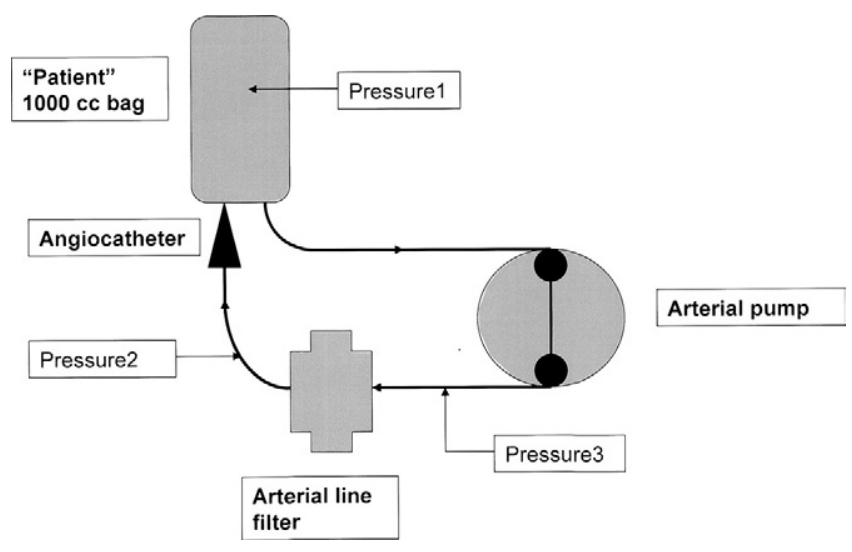

Figure 1. Cardiopulmonary bypass circuit.

This was attached to a 20-gauge spinal needle inserted into the drug administration port of the fluid bag. Arterial cannula pressure (pressure 2) and cardiopulmonary bypass circuit pressure (pressure 3) were measured with transducers on the heart-lung machine.

The circuit was primed with a $30 \%$ glycerol solution (SigmaAldrich, St Louis, Mo) to simulate the viscosity of whole blood. ${ }^{1,2}$ Catheters of gradually increasing diameter and length were in- serted into the drug administration port of the fluid bag and connected to the cardiopulmonary bypass circuit to simulate arterial cannulation. With each catheter, flows were increased in increments of $10 \mathrm{~mL} / \mathrm{min}$ until a maximum circuit pressure of 400 $\mathrm{mm} \mathrm{Hg}$ was achieved. The intravenous fluid bag pressure was maintained at $52 \mathrm{~mm} \mathrm{Hg}$. Data were recorded.

\section{Results}

Results are summarized in Figure 2. Catheter sizes increased from 24 to 14 gauge, and catheter lengths increased from 1 inch to 1.88 inches. Flow could not be established through the 24-gauge catheter without an unacceptably high arterial line pressure. From the next smallest catheter (22 gauge, 1 inch) to the largest catheter (14 gauge, 1.88 inches), maximum achievable flow rates ranged from 70 to $540 \mathrm{~mL} / \mathrm{min}$, respectively.

\section{Clinical Summary}

The patient was a 4-month-old boy with complex single ventricle heart disease consisting of double-inlet left ventricle, transposition of the great arteries, and pulmonary stenosis. On day 6 after birth and $2.1 \mathrm{~kg}$, he underwent placement of a 3.0-mm right modified Blalock-Taussig shunt through a midline sternotomy. He recovered well and was

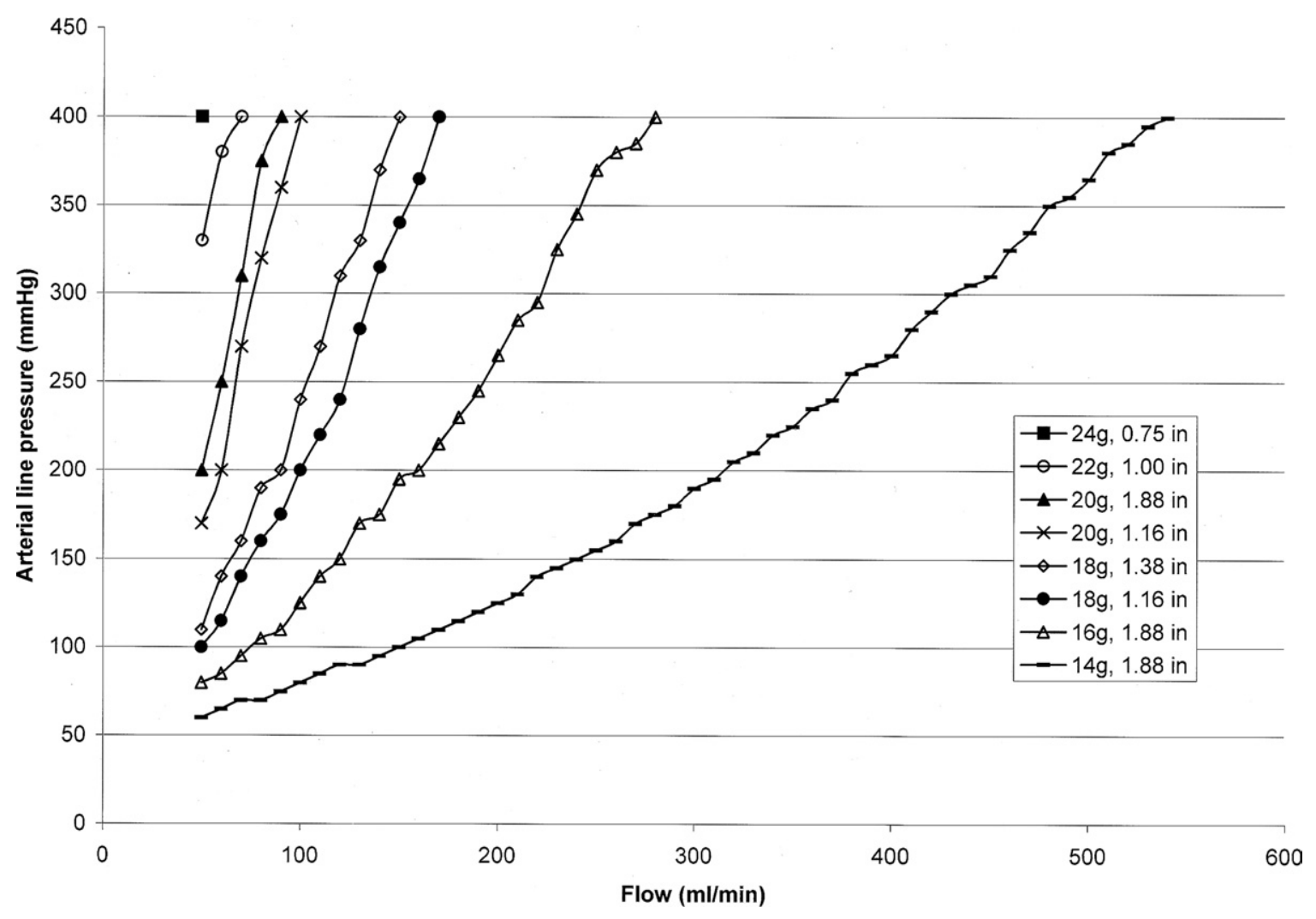

Figure 2. Catheter-dependent flow rates. 
taken to the operating room at 7 months of age and $6.3 \mathrm{~kg}$ for a bidirectional Glenn operation. The right atrium was entered during sternal re-entry.

An emergency cutdown in the left groin was performed exposing the common femoral artery. Full-dose heparin was administered. The artery was cannulated with a 14-gauge BD Angiocath (BD Medical). Pump suckers supplied venous return. Adequate flows and patient blood pressures were maintained.

Sternal re-entry was completed, the right atrium was repaired, and standard cannulation was performed. The aorta was cannulated with a $10 \mathrm{~F}$ Bio-Medicus cannula (Medtronic BioMedicus, Eden Prairie, Minn), and the right atrium and innominate vein were cannulated with $20 \mathrm{~F}$ and 10F Pacifico cannulas, respectively. The left femoral artery BD Angiocath was removed and the vessel was repaired with 7-0 Prolene suture (Ethicon, Inc, Somerville, NJ) in an interrupted fashion. Doppler ultrasound was used to confirm distal pulsatile blood flow.

The remainder of the operation proceeded as planned, the hospital course was otherwise uneventful, and the patient was discharged on postoperative day 5 .

\section{Discussion}

Peripheral cannulation for cardiopulmonary bypass can be performed electively in cases of aortic disease or in the presence of aneurysmal tissue adherent to the posterior aspect of the sternum. It can also be performed on an emergency basis in cases of complicated sternal re-entry. In adults, the technique of peripheral cannulation is quite feasible. Both the axillary and femoral arteries are common choices for adult peripheral cannulation and are adequately sized vessels to establish arterial inflow. Unfortunately, in small children these vessels are often extremely small and unsuitable for cannulation with standard pediatric arterial cannulas.

Although carotid artery cannulation in children is an attractive alternative, these sites are occasionally problem-

TABLE 1. Predicted common femoral artery diameter in children

\begin{tabular}{cccc}
\hline Weight (kg) & $\begin{array}{c}\text { 50th percentile } \\
\text { height (cm) }\end{array}$ & BMI & $\begin{array}{c}\text { Common femoral } \\
\text { artery (mm) }\end{array}$ \\
\hline 3 & 48.2 & 12.9 & 1.5 \\
4 & 53 & 14.2 & 1.6 \\
5 & 56.3 & 15.8 & 1.7 \\
6 & 60.5 & 16.4 & 1.9 \\
7 & 64.7 & 16.7 & 2.0 \\
8 & 68.3 & 17.1 & 2.1 \\
9 & 72.8 & 17 & 2.3 \\
10 & 77 & 17 & 2.4 \\
\hline
\end{tabular}

$B M I$, Body mass index. atic as well. Although they can be used if needed, these sites are often prepared out of the field with the anesthesiologists using the internal jugular veins for central access. In addition, a history of cannulation for extracorporeal membrane oxygenation with ligation of an ipsilateral carotid artery makes cannulation of the contralateral carotid artery worrisome.

It is our current practice during reoperative sternotomies to prepare the groins sterilely. Although we do not routinely place a catheter or guide wire in the femoral artery before sternal re-entry, this allows for urgent percutaneous or cutdown femoral artery cannulation. Once standard cannulation is achieved, peripheral cannulas should be removed to minimize the risk of ischemic limb complications.

For femoral cannulation, several studies have been performed to predict the size of femoral vessels in pediatric patients. Each has resulted in a calculation or nomogram based on various combinations of age, weight, height, body mass index, and/or body surface area. ${ }^{3-5}$ In one study, the best model for common femoral artery diameter was $-0.838+0.31$ height +0.046 body mass index. ${ }^{4}$ With this formula used for children between 3 and $10 \mathrm{~kg}$, the predicted common femoral artery ranges from 1.5 to $2.4 \mathrm{~mm}$ in size, respectively (Table 1).

Table 2 shows the relationships between French, gauge, and millimeter diameters. The smallest standard pediatric arterial cannula is an $8 \mathrm{~F}$-diameter cannula, which should accommodate a 2.6-mm vessel. However, the blunt tip often makes insertion into small vessels somewhat challenging. Peripheral intravenous catheters in the range of 14 to 24 gauge will accommodate blood vessels between 1.6 and 0.5 $\mathrm{mm}$ and are easily inserted.

This investigation's maximum achievable blood flow rates ranged from 70 to $540 \mathrm{~mL} / \mathrm{min}$. Necessary flow is determined by the size of the patient, metabolic demands, and the degree of cardiac injury. On the basis of standard flow rates in pediatric patients, the larger peripheral intravenous catheters can provide significant support. Larger gauge catheters (12 or 10 gauge), or those with shorter lengths, may be even more effective at supporting a small child during complicated sternal re-entry.

\section{TABLE 2. Unit conversions}

\begin{tabular}{ccc}
\hline French & Gauge & Millimeters \\
\hline $10 \mathrm{~F}$ & & 3.33 \\
$8 \mathrm{~F}$ & & 2.67 \\
& $14 \mathrm{~g}$ & 1.63 \\
& $16 \mathrm{~g}$ & 1.29 \\
& $18 \mathrm{~g}$ & 1.02 \\
& $20 \mathrm{~g}$ & 0.81 \\
& $22 \mathrm{~g}$ & 0.64 \\
& $24 \mathrm{~g}$ & 0.51 \\
\hline
\end{tabular}


Unfortunately, this cardiopulmonary bypass model does not account for all of properties of the human circulatory system, and it remains unclear what role coagulation and hemolysis may play.

\section{Conclusions}

Peripheral arterial cannulation may be lifesaving in cases of complicated sternal re-entry in children. Peripheral intravenous catheters can be used when vessels are too small for standard cannulas. Blood flow rates that provide adequate patient support while maintaining acceptable arterial line pressures are achievable with peripheral intravenous catheters until central cannulation can be accomplished safely.

\section{References}

1. Pohl M, Wendt MO, Werner S, Koch B, Lerche D. In vitro testing of artificial heart valves: comparison between Newtonian and nonNewtonian fluids. Artif Organs. 1996;20:37-46.

2. Helal M, Watts KC, Marble AE. Hemodynamic simulation of artificial networks, which include compliant and rigid bypass grafts. $J$ Biomech. 1994;27:277-87.

3. Kroger K, Nettelrodt J, Muntsches C, Neudorf U, Feuersenger A, Rudofsky G, et al. Impact of age, height, and body mass index on arterial diameters in infants and children: a model for predicting femoral artery diameters prior to cardiovascular procedures. J Endovasc Ther. 2004;11:419-23.

4. Munk A, Darge K, Wiesel M, Troeger J. Diameter of the infrarenal aorta and the iliac arteries in children: ultrasound measurements. Transplantation. 2002;73:631-5.

5. Sandgren T, Sonesson B, Ahlgren R, Lanne T. The diameter of the common femoral artery in healthy human: influence of sex, age, and body size. J Vasc Surg. 1999;29:503-10. 